\title{
ooperación
}

internacional en la Cuenca del Pacífico

\section{El proceso histórico de la integración regional: de la gobernabilidad mundial al regionalismo supranacional}

Introducción

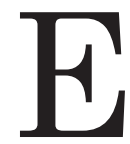

l Estado-nación pareciera estar encontrando los límites de su efectividad como garante del bienestar en la sociedad del siglo XXI. Algunos lo llaman modernidad tardía o reciente, segunda modernidad, ${ }^{1}$ tiempo social tardo moderno ${ }^{2}$ o sobremodernidad; ${ }^{3}$ modernidad reflexiva, ${ }^{4}$ contramodernidad, ${ }^{5}$ posmodernidad; ${ }^{6}$ sociedad postradicional, sociedad postindustrial o poscapitalista, ${ }^{7}$ hipermodernidad; sociedad informacional, sociedad del conocimiento, era de la infor-

Licenciado en Estudios Internacionales. Estudiante de la maestría en Ciencias Sociales de la Universidad de Guadalajara y de la maestría en Estudios Contemporáneos de América Latina del Proyecto Alfa-Amelat XXI. ORCID http://orcid.org/0000-0002-4304-3831 Correo electró-nico: demgdl@gmail.com. mación y de las revoluciones tecnológicas ${ }^{8}$ o era del globalismo. ${ }^{9}$ Lo cierto es que estamos ante una nueva experiencia de reorganización del tiempo y del espacio a causa del aceleramiento de los flujos de personas, bienes e ideas.

Este mundo, que se encuentra en plena reconfiguración, está siendo transmutado por, al menos, cuatro procesos: ${ }^{10}$ localización, posnacionalización, regionalización y globalización. De estos cuatro procesos posmodernos de reestructuración socioespacial, ha sido principalmente la globalización la que ha impactado a nivel mundial desatando tres movimientos complementarios que transforman el tiempo (con el paso de la modernidad a la posmodernidad), el espacio (con el paso de los lugares a los no lugares) y la imagen (con el paso de lo real a lo virtual). ${ }^{11}$

MÉXICO YLACUENCADEL PACÍFICO vol. 10, núm. 30 / septiembre-diciembre de 2007 
La globalización, como proceso reformador de la modernidad, tiene sus orígenes en la década de los sesenta con la conquista del espacio, la creación de Internet, la producción masiva de computadoras personales, el desarrollo de una telefonía celular con alcance planetario, el abaratamiento de los medios de transporte internacionales y el desarrollo de industrias culturales de proyección global. La globalización — que no ha sido exclusivamente occidental ni mucho menos una simple continuación del imperialismo-es un complejísimo fenómeno pluricausal y multidimensional, que ha venido a socavar las ideas sobre las cuales estaba sustentado el sistema mundo-moderno y a dinamizar transformaciones políticas, sociales y económicas en el mundo, dando lugar a una crisis-periodo ${ }^{12}$ con propiedades universalizantes y de gran impacto en la vida cotidiana. ${ }^{13}$ Es por ello que, al ser debatida la modernidad, su principal constructo político-social, el Estado-nación, se encuentra también fuertemente cuestionado dando pie a innovadoras formas de organización político-sociales: en lo local, las ciudades están sufriendo cambios significativos en su infraestructura, actividades económicas, vida social y cultural para adaptarse a las exigencias de la competitividad global; en lo nacional, si bien el tradicional Estado-nación está delegando tanto funciones como autoridad política (soberanía) hacia los niveles supranacional y global, al tiempo que se "disuelven" las fronteras; en lo global, se está configurando una sociedad red ${ }^{14}$ que tiende a estandarizarse $u$ homogenizarse culturalmente, mientras que emergen organizaciones y regímenes que condicionan cada vez más el comportamiento del Estado. Sin embargo, entre lo global y lo local los
Estados-nacionales han avanzado en la conformación de novedosos y complejos sistemas que, a nivel regional, buscan garantizar la paz, coadyuvar al desarrollo y promover el bienestar entre las sociedades involucradas.

Para poder ver con claridad las alternativas que ofrece la integración regional como alternativa a la nueva realidad posmoderna, es importante saber cómo hemos llegado hasta ella y de qué forma se deberá trabajar para superar las limitaciones del sistema-mundo ya declinante. ¿Cuáles han sido los ciclos o etapas de la integración regional en el mundo? ¿Cómo están impactando las teorías de la integración regional el cuerpo epistemológico de las relaciones internacionales? Este trabajo no pretende dar respuestas a todas las interrogantes económicas, culturales, sociales o políticas de la integración regional, sino busca estudiar los intentos de gobernabilidad regional emprendidos en la modernidad para identificar las teorías, causas y medios que llevaron a los Estados nacionales a explorar formas más efectivas de armonización supranacional.

\section{Del fracaso de la gobernabilidad mundial a la gobernabilidad subsistémica regional}

Si bien el sistema internacional ha evolucionado en su dimensión política a lo largo de los siglos hasta la actualidad, sus orígenes se remontan al 24 de octubre de 1648 en Westfalia, Renania del Norte, la actual Alemania. La "Paz de Westfalia" fue la primera que estableció un régimen de equilibrio entre los Estados modernos dentro de lo que se conoce como sistema internacional clásico. ${ }^{15}$ 
El sistema internacional westfaliano clásico: de la paz de Westfalia a la santa alianza/concierto de Europa

En su etapa clásica (1648-1814/15) el sistema internacional se concibe sólo bajo una óptica eurocentrista, ya que en el resto de las regiones del mundo no existía aún el actor indispensable (Estado-nación) para su inserción en el sistema internacional: en Medio Oriente el imperio otomano intentaba restaurar viejas instituciones (Nizam-i Cedid, 1829-1855); en el Extremo Oriente el Japón feudal (periodo Edo, 1600-1868) se aislaba respecto a Occidente, India permanecía bajo control del imperio mongol (1526-1739) y el resto de la región pasaría a ser controlada por el imperio chino (dinastía Qing, 1644-1912); mientras que Norteamérica, América Latina, África y Oceanía se encontraban supeditadas al yugo colonial europeo (ya sea de Portugal, España, Francia, Holanda o Inglaterra). Por ende se puede señalar que, por un lado, el sistema internacional clásico no tiene un alcance mundial sino sólo abarca un subsistema circunscrito exclusivamente a Europa Occidental y el imperio ruso; pero, por otro lado, el actor por excelencia de este subsistema (el europeo) es el Estado.

No obstante, un subsistema difícilmente puede vivir en jarrones cerrados y su funcionamiento interno dependerá de todo aquello que ocurra dentro de los subsistemas vecinos, por la permanente interacción que guardan. ${ }^{16}$ Por ello, todo el sistema mundo-moderno comenzó a ser influenciado por el modelo estatocéntrico europeo a causa, en buena medida, del rol colonizador de los europeos en los siglos XVI, XVII y XVIII vía la imposición de sus ideas socioculturales y la propagación de sus formas de organización política. De esta manera, a inicios del siglo XIX el siste- ma interestatal desarrollado a partir de los acuerdos de Westfalia se había impuesto prácticamente sobre todas las demás civilizaciones ${ }^{17} \mathrm{y}$ subsistemas de relaciones tribales que existían hasta esos momentos en las demás regiones del mundo. ${ }^{18}$

En esta etapa histórica que va de 1648 a 1815 no es posible identificar algún intento de gobernabilidad interestatal o, en palabras de Bobbio, un "tercero sobre las partes", debido al reciente surgimiento de los Estados y a la mínima interdependencia entre ellos. ${ }^{19}$ Empero, con el fin de las guerras napoleónicas Europa transitaría hacia la búsqueda del equilibrio de poder y un mínimo de gobernabilidad entre las potencias a través del Congreso de Viena y del sistema de congresos que le prosiguió. Este sistema de congresos alcanzaría vigencia y funcionalidad por casi un siglo, desde inicios del siglo XIX hasta el final de la Primera Guerra Mundial.

Al tiempo que las relaciones entre los Estados-nación europeos se autorregulaban por medio de este mecanismo semiinstitucionalizado de gobernabilidad como lo fue el Concierto de Europa, en el resto del mundo comenzaron a formarse e insertarse en el sistema interestatal-internacional nuevos actores estatales: en Asia, India permanecía bajo el yugo colonial británico hasta mediados del siglo Xx; Japón, con el emperador Meiji Tenno (restauración Meiji, 1868-1912) se propuso hacer de la nación nipona una potencia mundial embarcándose para ello, al interior, en una política de modernización de las instituciones políticas y sociales y, al exterior, en una política expansiva; ${ }^{20}$ mientras que China se atrincheraba en su territorio frente a las pretensiones imperialistas de las principales potencias europeas y Estados Unidos. De esta manera, al tiempo que se consolidaban los Estados nacionales en 
Asia, un nuevo subsistema regional (el asiático) se iba configurando en el sistema mundial que se encontraba, a su vez, determinado y supeditado al subsistema existente más antiguo (el europeo). Sin embargo, a diferencia del sistema europeo y del sistema americano, durante el siglo XIX no fue posible en Asia caminar en aras de un mecanismo de gobernabilidad subsistémico, en parte por las colisionadas ambiciones de cada potencia en la región, pero también por las cruentas rivalidades histórico-culturales prevalecientes entre las naciones asiáticas.

En África la hegemonía del sistema europeo fue prácticamente absoluta. Prueba de ello fue el congreso celebrado en Berlín a partir de noviembre de 1884, donde los Estados-nación europeos se encontraron sin la presencia de un solo representante africano, para repartirse el continente.

Por su parte, las relaciones internacionales de los Estados nacionales del continente americano - una vez independizados del colonialismo europeo- mostraron un devenir distinto en comparación con los otros subsistemas regionales. Mientras que las potencias europeas se enfrascaban en una lucha para detener el avance del imperio francés de Napoleón Bonaparte, nacía el sistema interamericano: Estados Unidos se afirmaba como una nueva potencia mundial y en toda América Latina nacieron un puñado de nuevos Estadosnación: México, las Provincias Unidas del Centro de América, las Provincias Unidas del Río de la Plata, Paraguay, Chile, la República de la Gran Colombia, Perú, Bolivia y Brasil. El nuevo subsistema de Estadosnación en América pudo llegar más lejos que Europa en la gobernabilidad regional, encontrando sus fundamentos en los principios de "no intervención", la "doctrina americana de reconocimiento" ${ }^{\text {"21 }} \mathrm{y}$ en un sis- tema de conferencias continentales similar a las conferencias europeas, pero que las superaban en contenido ya que, además de brindar armonía en el subsistema, buscaba la creación de una confederación dotada de un ejército interamericano para la defensa común frente a los recelos colonialistas europeos, las aspiraciones expansionistas estadounidenses y las apetencias subhegemónicas brasileñas.

Cabe mencionar que desde sus preludios el sistema interamericano se dividió ideológica y culturalmente en dos: al norte, Estados Unidos y Canadá, quienes lograron constituirse rápidamente como potencias y buscaron garantizarse "títulos de exclusividad" sobre el resto del continente promoviendo el panamericanismo; y al centro y sur, América Latina, que pretendió fallidamente constituirse en una gran confederación de repúblicas bajo una ideología hispanoamericanista. En este sentido, mientras que la iniciativa de las Conferencias Panamericanas (la primera de éstas se celebró en Washington en 1889 y daría pie, un año después, a la creación de la Unión Panamericana) fuera comandada por Estados Unidos buscando superar la informalidad del concierto de Europa mediante la creación de un marco de gobernabilidad subsistémica que más tarde desembocaría en la actual Organización de Estados Americanos (OEA), los Congresos Hispanoamericanos contribuyeron al desarrollo — al menos teórico- de un esquema supranacional de carácter federalista ${ }^{22}$ donde se preveía la creación de una "confederación de estados hispanoamericanos", según lo postulaban algunos acuerdos ratificados como: ${ }^{23}$ los Tratados de Amistad, Liga y Confederación Perpetua (1824); el Tratado de Confederación (1848); el Tratado Continental o Tratado que fija las bases de unión de las Repú- 
blicas Americanas (1856); el Proyecto de Tratado de Alianza y Confederación (1856); el Tratado de Unión y Alianza Defensiva (1864) o el Proyecto de Tratado para fundar una Liga Sudamericana (1865).

Sistema internacional moderno:

Sociedad de Naciones (1919-1945) y Naciones Unidas (1946- $\dot{2}$ ?)

La Primera Guerra Mundial (1914-1919) fue el primer conflicto interestatal-internacional que involucró a actores de todos los subsistemas del mundo: casi todos los Estados-nación europeos (incluidos los Balcanes) y los imperios centrales (Alemania, Austria-Hungría, Bulgaria e imperio otomano) participaron; del continente asiático, involucró a Rusia y Japón; algunas batallas fueron libradas en territorios africanos; mientras que Estados Unidos, la nueva potencia mundial, ejercería un papel cardinal en el desenlace de la guerra. Todos ellos se enfrascaron en un conflicto internacional que, si bien tuvo sus primeras disputas en el territorio del Imperio austro-húngaro y Serbia, se vio avivado por los ánimos nacionalistas, el afanoso armamentismo de la época y la pugna políticoeconómica entre los Estados-nación, hasta alcanzar magnitudes descomunales.

Frente a este evento, que afectó a todo el sistema internacional, los intentos semiinstitucionalizados de gobernabilidad a nivel subsistémico regional — como el Concierto de Europa o los Congresos Hispanoamericanos/Panamericanos-realizados hasta esos momentos, se vieron rebasados: el nuevo sistema internacional, que comenzaba a tener problemas y retos de alcance global, requería un nuevo actor regulador que estuviera por encima de los Estados-nación y de los subsistemas continentales. Así, bajo la iniciativa idealista del presidente estadounidense Thomas Woodrow Wilson (1856-1924) y del político sudafricano Jan Christiaan Smuts (18701950), la Sociedad de Naciones fue creada con el objetivo de garantizar la paz a través de la seguridad colectiva y la cooperación, dotándose para ello de una estructura institucional cuyos órganos más importantes serían: el Consejo, la Asamblea, la Secretaría Permanente, la Corte Permanente de Justicia Internacional y la Comisión de Mandatos.

Lamentablemente, en lo que respecta a los mecanismos institucionales de gobernabilidad global el fracaso de la Sociedad de Naciones fue evidente, ya que no pudo prosperar y evitar la Segunda Guerra Mundial. Aun así, muchos aspectos de la Sociedad fueron retomados en la reunión Dumbarton Oaks (otoño de 1944) para cimentar una nueva organización internacional: ${ }^{24}$ la Organización de las Naciones Unidas. Con todo, resulta significativo que, al mismo tiempo que se avanzaba en un nuevo mecanismo de gobernabilidad universal que abarcara todo el sistema interestatal-internacional en esta nueva etapa histórica que inició en 1919, cada uno de los subsistemas regionales (en Europa, África, Asia y América) decidió garantizarse internamente la paz y el progreso a través de nuevas instituciones que se encontraran efectivamente por encima de los Estados-nación, para lo cual se crearon los sistemas de integración regional.

\section{Hacia la formación del sistema interregional}

Aun cuando cada uno de los sistemas de integración regional desarrollados en el mundo son procesos - y como tales son imperfectos, inacabados y disímiles entre sí-,

MÉXICO YLACUENCADEL PACÍFICO vol. 10, núm. 30 / septiembre - diciembre de 2007 
es posible observar en su devenir histórico varios ciclos o etapas (véase esquema 1): una primera etapa que va de 1957 a 1975 y pudiera ser nombrada como "periodo clásico", se caracteriza por la constitución de sistemas que implementaron políticas integracionistas de corte funcionalista y neofederalista; luego, una etapa de "estancamiento" que iría aproximadamente de 1976 a 1989, en la cual los sistemas de integración regional fueron meticulosamente cuestionados por las críticas intergubernamentalistas provenientes del realismo político, embutiéndolos en crisis profundas que pusieron en duda su continuidad; por último y durante los años noventa, una etapa que ha sido identificada por algunos como "nuevo regionalismo", cuando fueron reformuladas antiguas propuestas en un neofuncionalismo que permitió superar los cuestionamientos intergubernamentalistas planteando nuevos modelos y representaciones político-sociales supranacionales regionales, nuevas normas jurídico-institucionales internacionales y nuevos derroteros económicos que coadyuvarían en la evolución de los sistemas de integración regional hasta convertirlos en verdaderos subsistemas del sistema internacional. Recientemente, a partir del año 2000, parece iniciar una nueva etapa ("fusión") en un fenómeno sin precedentes: sistemas de integración subregionales han comenzado, por un lado, a flexibilizar sus objetivos y plazos para dar cabida a la participación e incorporación de nuevos Estados-nación; por otro lado, están acercándose a otros sistemas de integración subregionales fortaleciendo sus vínculos entre sí, en miras a una posible fusión.

Primera etapa (1957-1975): periodo clásico

En esta etapa de la historia las élites gubernamentales observaron un "desgaste" del Estado-nación moderno, manifestado en la incapacidad de este constructo político-social para satisfacer las necesidades básicas de su población, de manera que se buscó la creación y desarrollo de una forma de autoridad basada en una red de organizaciones internacionales a las cuales los Estados nacionales irían transfiriendo

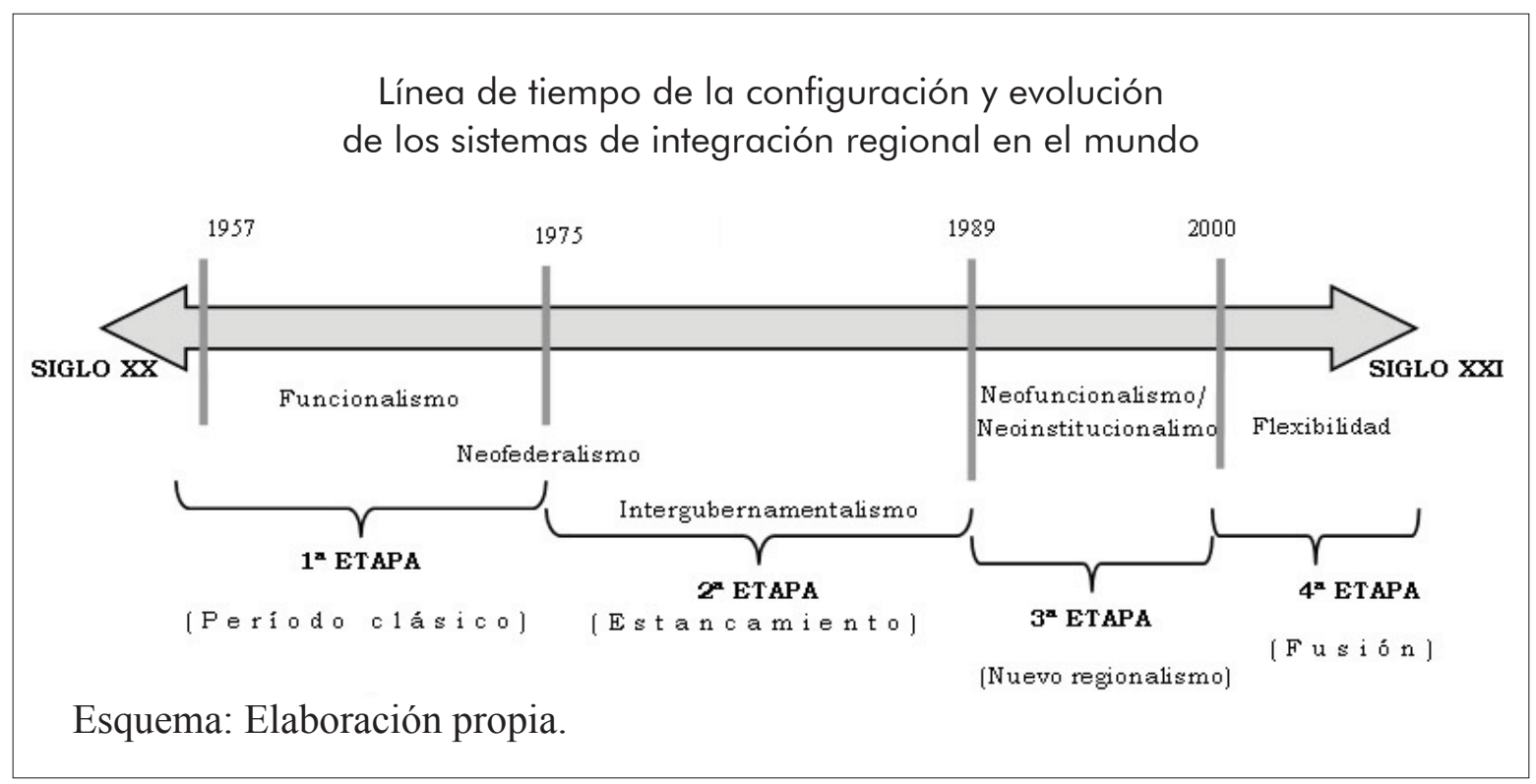


soberanía hasta crear una nueva autoridad con capacidades supranacionales. Este nuevo ente político-institucional, por un lado, limitaría las actitudes ultranacionalistas (causa de enfrentamientos bélicos internacionales), pero por otro lado asumiría la gestión de sectores concretos para instaurar un "sistema aterritorial/ descentralizado de transacciones" y que sería el mecanismo encargado de satisfacer las necesidades básicas de los ciudadanos. Desde esos momentos la integración regional comienza a ser concebida, como la definí previamente, la relación o el proceso de correlación entre porciones determinadas de la superficie terrestre correspondientes a dos o más Estados-nación, que comparten objetivos preconcebidos y/o características específicas y que vuelve interdependientes a los Estados-nación involucrados haciéndolos poseedores de propiedades sistémicas de las cuales carecerían si se mantuvieran aislados. ${ }^{25}$

Las primeras estrategias de integración regional se pueden enmarcar en la corriente teórica que fue conocida como funcionalismo. Éste, que tiene sus bases en la práctica de una ingeniería social (socialismo fabiano británico) y el principio de "la forma sigue la función" (principio spenceriano), fue desarrollado en Europa durante el periodo de entreguerras. Gracias a sus aportaciones, David Mitrany es considerado como el fundador de esta corriente, mientras que Ernest Haas fue un destacado continuador.

Con algunas experiencias integracionistas previas como el Benelux, ${ }^{26}$ fue puesta en marcha - bajo sugerencia del Plan Schuman- la Comunidad Económica del Carbón y del Acero (CECA) por la República Federal de Alemania, Francia, Italia, Luxemburgo y los Países Bajos en 1951, primer organismo supranacional con capacidad decisoria efectiva sobre dos productos clave para la economía: el acero, elemento indispensable para la creación de armamento, y el carbón, producto necesario para la industria y el desarrollo. ${ }^{27}$

En forma complementaria al incipiente modelo de integración político-económica de la CECA, se pusieron en marcha la Comunidad Económica Europea (CEE) y la Comunidad Europea de Energía Atómica (Euratom) por los Tratados de Roma de 1957. Las tres comunidades (CECA, CEE y Euratom) quedarían agrupadas en una sola bajo el Tratado de Fusión de 1965.

Dada la "cesión de soberanía nacional" que implicaba participar de un proyecto de integración regional (como el propuesto por las "comunidades europeas"), esta primera etapa fue emprendida con reticencias por parte de muchos Estados-nación, que concebían la cesión de soberanía como una amenaza para la consecución de sus intereses nacionales. Aun así, la impresionante recuperación económica de la vieja Europa en el escenario posbélico se presentaba como una seductora garantía de que la integración resolvería los rezagos de muchos países subdesarrollados o en vías de desarrollo. De esta forma, a partir de la década de los sesenta el mundo entero comenzó institucionalmente a regionalizarse:

- En 1960 por el Convenio de Estocolmo, la Asociación Europea de Libre Comercio (European Free Trade Association, EFTA) entre Austria, Dinamarca, Reino Unido, Noruega, Portugal, Suecia, Suiza, Finlandia e Islandia.

- En 1960 con el Tratado de Montevideo se pone en marcha la Asociación Latinoamericana de Libre Comercio (ALALC) entre Argentina, Brasil, Chile, México, Paraguay, Perú, Uruguay, Colombia, Ecuador, Venezuela y Bolivia.

MÉXICO YLACUENCADEL PACÍFICO vol. 10, núm. 30 / septiembre-diciembre de 2007 
- En 1960 con el Tratado de Managua es instituido el Mercado Común Centroamericano (MCCA) entre Guatemala, Honduras, El Salvador, Nicaragua y Costa Rica.

- En 1966 por el Acuerdo de la Bahía Dickenson se instaura la Asociación de Libre Comercio del Caribe (Caribbean Free Trade Agreement, Carifta) entre los gobiernos de Antigua, Barbados y la Guyana Británica.

- En 1966, por el Tratado de Brazzaville, la Unión Aduanera y Económica del África Central (Union Douaniere et Économique de l'Afrique Centrale, UDEAC) es puesta en marcha por Camerún, la República del África Central, Chad, la República del Congo, Guinea Ecuatorial y Gabón.

- En 1967 la Comunidad Europea (CE, a partir de la fusión CECA/CEE/Euratom) con Francia, Bélgica, Luxemburgo, Países Bajos, Italia y la República Federal de Alemania.

- En 1967 con la Declaración de Bangkok es constituida la Asociación de Naciones del Sudeste Asiático (Association of South Eastern Asian Nations, ASEAN) por Indonesia, Malasia, Filipinas, Singapur y Tailandia.

- En 1969 con el Acuerdo de Cartagena se funda el Pacto Andino con la participación de Bolivia, Colombia, Chile, Ecuador y Perú.

- En 1969 se integra la Unión Aduanera Sudafricana (Southern African Customs Union, SACU) entre Botswana, Lesotho, Namibia, República de Sudáfrica y Swazilandia.

- En 1971 el Foro del Pacífico Sur (South Pacific Forum) es integrado por Australia, las Islas Cook, Micronesia, Fiji, Kiribati, las Islas Marshall, Nauru, Nueva Zelanda, Niue, Palau, Papúa
Nueva Guinea, Samoa, las Islas Salomón, Tonga, Tuvalu y Vanuatu.

- En 1975 con la firma del Tratado de Lagos es puesta en marcha la Comunidad Económica de los Estados de África Occidental (Economic Community of West African States, ECOWAS) entre Benín, Burkina Faso, Cabo Verde, Costa de Marfil, Gambia, Ghana, Guinea, Guinea-Bissau, Liberia, Malí, Mauritania, Níger, Nigeria, Senegal, Sierra Leona y Togo.

- En 1976 la Comunidad Económica de los Países de los Grandes Lagos (Communauté Economique des Pays des Grands Lacs, CEPGL) es fundada por la República Democrática del Congo, Ruanda y Burundi.

Para concluir con esta primera etapa, habría que hacer mención del impulso que brindaron a los procesos de integración regional las propuestas neofederalistas, las cuales planteaban desarrollar entramados institucionales supranacionales similares a aquellos desarrollados con el Plan Schuman en la CECA. Los neofederalistas - entre quienes se pueden mencionar Dusan Sidjanski, Francesco Capotorti y John Pinder- proponían una reforma federal de la estructura competencial que, por un lado, tuviera en cuenta el enraizamiento del principio de legitimación democrática en los parlamentos nacionales, así como la justa consideración de la soberanía nacional y las exigencias de autonomía; pero, por otro lado, garantizaran la apertura a la acción supranacional. Para alcanzar esto, el neofederalismo se basa en dos componentes centrales: el principio de subsidiariedad (o exacta adecuación) y el principio de participación. Por su parte, en sus propuestas político-jurídicas el neofederalismo planteaba la creación de un cuerpo 
ejecutivo bicéfalo formado por una comisión (con representantes plenipotenciarios que desempeñarían los roles de un gobierno comunitario) y un consejo (constituido por los jefes de Estado y de gobierno, más el presidente de la comisión); la formación de un cuerpo legislativo compuesto por un parlamento (que tendría un sistema electoral común y reglas homogéneas para la división de circunscripciones) y un senado (cuyos integrantes serían elegidos por los parlamentos nacionales y por el electorado organizado en circunscripciones nacionales y regionales); mientras que las funciones jurisdiccionales corresponderían al Tribunal de Justicia. Estos órganos serían apoyados por una red de grupos técnicos especializados. ${ }^{28}$

En esta primera etapa los niveles de integración social (y política) son mínimos, ya que muchos de los Estados nacionales que decidieron participar de algún esquema de integración regional (en esta etapa embrionaria no pueden ser considerados aún como sistemas) se mantuvieron reticentes a las dinámicas comunitarias, ya que concebían la cesión de soberanía como una amenaza para la consecución de sus intereses nacionales.

Segunda etapa (1976-1989): estancamiento

Como podemos observar, el periodo clásico de las teorías de integración regional, que abarca el funcionalismo y el neofederalismo (tomando en cuenta este último, se desenvolvería levemente y de manera intermitente), se extendería hasta inicios de la década de los ochenta, pero a partir de estos momentos y hasta los años noventa todo el sistema internacional transitaría por una oleada de "realismo político" en sus concepciones sobre la integración regional, de modo que todas las regiones y subregiones sin excepción darían un viraje en sus políticas hacia un intergubernamentalismo centrado en las relaciones de poder entre los Estados miembros, reflejo del escepticismo acerca de la integración regional.

A partir del segundo lustro de la década de los setenta y hasta finales de la de los noventa, la regionalización fue meticulosamente cuestionada, provocando crisis política y estancamiento económico en la mayoría de los procesos de integración regional. Estas críticas, que se acercan al realismo político de las relaciones internacionales, se pueden ubicar dentro de una segunda etapa (1976-1989) que ponía de relieve las relaciones intergubernamentales en los procesos de integración. Entre los teóricos de las relaciones internacionales que aportaron al desarrollo del intergubernamentalismo en la integración regional podemos encontrar a Stanley Hoffmann, Robert Keohane, Paul Taylor y Andrew Moravcsik.

En esta etapa, una de las principales críticas a la integración regional apuntaba que los promotores nunca fueron capaces de reconocer la diferencia fundamental entre los temas de "baja política" (temas técnico-económicos directamente relacionados con el bienestar de la población) y los de "alta política" (relacionados con la propia supervivencia del Estado, como por ejemplo la política exterior o la defensa). En este sentido, se amonestó a los teóricos y a los políticos integracionistas al suponer que, aun cuando los Estados-nación se integren y cooperen en temas de "baja política", nunca lograrían ponerse de acuerdo en temas de "alta política" y mostrarían hermetismo frente a la colaboración en asuntos que pusieran en entredicho la soberanía nacional. Además, aunque los gobiernos cedan soberanía (pero nunca 
autoridad total) a las instituciones comunitarias, sería con el objetivo de supervisar cuidadosamente la actuación en sus tareas de ejecución, ya que la capacidad real de garantizar los acuerdos radica en último término en los intereses nacionales de los Estados-nación.

Estas críticas a la integración supranacional llegaron a afectar profundamente a todos los sistemas de integración regional desacelerándolos y metiéndolos en crisis profundas que pusieron en duda su continuidad.

Así, aunque durante década y media algunos de los procesos de integración regional vivieron profundas crisis que pusieron en entredicho su existencia, otros muchos fueron, en lo interno, redefinidos y reorientados, pero también en lo externo, ampliados con la incorporación de nuevos miembros que se habían mantenido al margen de los acuerdos constitutivos originales. De esta manera y bajo un contexto sistémico de decreciente bipolaridad, el orden geopolítico mundial se ve modificado por las transformaciones de los esquemas de integración:

- La Comunidad Europea es vigorizada a costa de la EFTA, ya que en 1973 Reino Unido y Dinamarca, y luego en 1986 Portugal, abandonaban el bloque preponderantemente nórdico para integrarse a la futura Unión Europea en uno de sus tantos procesos de ampliación (Dinamarca, Irlanda y Reino Unido en 1973; Grecia en 1981; Portugal y España en 1986).

- En 1973 con el Tratado de Chaguaramas, la Carifta se transformaba en la Comunidad del Caribe (Caribbean Community, Caricom), la cual estaría integrada por los tres miembros originales de la antigua Área de Libre
Comercio Caribeña (Antigua, Barbados y la Guyana Británica) más Belice, Dominica, Granada, Jamaica, San Kitts y Nevis, San Vicente y las Granadinas, Trinidad y Tobago, Montserrat y Santa Lucía, y se le brinda a la nueva Comunidad de un entramado institucional más complejo.

- En 1980, con la Declaración de Lusaka, se integra la Conferencia de Coordinación para el Desarrollo Sudafricano (Southern African Development Coordination Conference, SADCC) entre los antiguos miembros de la SACU (Botswana, Lesotho, Swazilandia) más Angola, Malawi, Mozambique, Tanzania, Zambia y Zimbabwe, y a la cual se le dotó de una institucionalidad que incluía un consejo de ministros y un secretariado.

- En 1980 la ALALC se reestructura para dar lugar a la Asociación Latinoamericana de Libre Comercio (ALADI).

- En 1981 es creada la Comunidad Económica de los Estados del África Central (CEEAS) a partir de la UDEAC, la CEPGL y la incorporación de Santo Tomé y Príncipe, haciéndose valer de una institucionalidad más compleja que la de sus antecesoras.

- En 1984 Brunei se incorpora a la ASEAN.

- En 1987, poco después de la salida de Chile y de la incorporación de Venezuela al bloque, el Pacto Andino se robustece por medio del Protocolo de Quito e incorporando oficialmente instituciones como el Consejo Andino de Ministros de Relaciones Exteriores, la Comisión, el Parlamento y el Tribunal de Justicia.

- En 1985 la Asociación Surasiática para la Cooperación Regional (South Asian for Regional Cooperation, SAARC) es 
creada por Afganistán, Bangla Desh, Bhután, India, las Islas Maldivas, Nepal, Pakistán y Sri Lanka, aunque con un entramado institucional débil que se limitaría a regular la cooperación subregional.

- En 1989 se celebra la primera Cumbre de la Unión del Maghreb Árabe (UMA) con la participación de Argelia, Libia, Mauritania, Maruecos y Túnez. Éste sería un esquema regional caracterizado por un mínimo de institucionalidad encargada de regular la cooperación internacional.

Desde la totalidad del sistema internacional, la Guerra Fría permitió que operaran en el mundo a lo largo de esta segunda etapa de la integración regional (1976-1989) dos sistemas ideológicos: el capitalista y el socialista. Estos dos sistemas, que compitieron política y militarmente, coadyuvaron también a que las superpotencias afianzaran su posición globalmente al concluir la Segunda Guerra Mundial. Sin embargo, el descontento social en la URSS retenido por décadas, acabó por desbordar a este sistema, echando por tierra el modelo socialista y obligando a reformas políticas que tuvieron como consecuencias inmediatas la reunificación alemana, la disolución En el escenario de la globalización del Siglo XX, los Estados-nación han dispuesto sus códigos geopolíticos en una serie de círculos concéntricos que van desde lo global hasta lo subregional con el objetivo de reducir su vulnerabilidad y mejorar

sus condiciones de negociación internacional de la Unión Soviética, la desaparición del bloque soviético y el fin del enfrentamiento bipolar.

En este nuevo escenario posbipolar comienza a esbozarse un nuevo orden mundial que, si bien pudiera aún no estar completamente definido, podría inaugurar un nuevo ciclo geopolítico con características muy distintas a los ciclos observados durante los periodos clásico y de Sociedad de Naciones/Naciones Unidas del sistema internacional.

Tercera etapa (1990-2000): nuevo regionalismo

Con el derrumbe del bloque socialista y la hegemonía del neoliberalismo como doctrina económica, se consolidaron tendencias productivas y de comercio que han trastocado aún más las relaciones económicas y de poder entre los Estados-nación, de manera que la integración regional volvió a ser vista, ahora por el neofuncionalismo, como un instrumento eficaz para lograr una mejor inserción y un mayor poder de negociación en el nuevo escenario mundial.

En el escenario de la globalización del siglo XX los Estados-nación han dispuesto sus códigos geopolíticos en una serie de círculos concéntricos ${ }^{29}$ que van desde lo global hasta lo subregional, con el objetivo de reducir su vulnerabilidad y mejorar sus condiciones de negociación internacional. Dentro de esta estrategia, a nivel regional fueron retomadas las críticas expuestas por los intergubernamentalistas. Así, los proyectos de integración regional comenzaron a plantearse nuevas ideas, nuevos modelos y representaciones, nuevas normas jurídicointernacionales y nuevas políticas que los 
llevaron a evolucionar para convertirse en verdaderos subsistemas del sistema internacional, es decir, sistemas regionales con: dinámicas económicas coordinadas, entramados político-institucionales supranacionales, élites gubernamentales y burocracias incipientemente supranacionales, mecanismos de gobernabilidad multinivel, códigos geopolíticos propios y una sociedad civil crecientemente regional.

En esta tercera etapa (1990-2000) se ha primado el rol de las instituciones. Según el neoinstitucionalismo desarrollado por Simon J. Bulmer, W. Sandholtz, A. Stone Sweet, Neil Fligstein y G. Majone, las instituciones-estructuras políticas (policy) deben entenderse con mayor amplitud que la estrictamente jurídica, abarcando las formales e informales, dado que contribuyen a configurar el propio juego político (politics), tienen un impacto sobre el resultado de las políticas (policy outcome) y pueden devenir en actores políticos. Aun cuando la representación y eficiencia son problemas de las mismas instituciones, éstas han asumido funciones de regulación administrativa, al tiempo que han incorporado a los políticos con base electoral (jefes de Estado y de gobierno), ya que su legitimidad y liderazgo resultan imprescindibles para las dinámicas regionales.

Asimismo, durante los años noventa se pensó, bajo una renovada óptica funcionalista (entre los teóricos neofuncionalistas más destacados tenemos a Ernest Hass, Leon N. Lindberg, Joseph S. Nye y Philippe C. Schmitter) que - como consecuencia del alto nivel de interdependencia entre los diferentes sectores de las economías industrializadas modernas - la integración en un sector determinado necesitaría la integración de sectores adyacentes a tal grado que la integración de los sectores técnico-económicos acabaría "desbordándo- se" (spillover) hasta alcanzar el terreno de lo sociocultural (dando pie a nueva identidad social regional) y de lo político (alcanzando las áreas de la seguridad y la defensa, que serían gestionadas en un nivel regional y no nacional). En algunos sistemas de integración regional la realidad parece haber alcanzado a la teoría. Para lograrlo fueron de suma importancia los apuntes de Nye, quien proponía dar entrada a los políticos con base electoral, ya que su legitimidad y liderazgo resultan imprescindibles en los sistemas de integración crecientemente politizados: "una vez que admitimos que las decisiones importantes que afectan al proceso de integración deben ser canalizadas a través del liderazgo político legitimador, enriquecemos grandemente el modelo". ${ }^{30}$

En función de esta óptica neoinstitucionalista/neofuncionalista, los esquemas de integración en el mundo evolucionaron de la siguiente forma:

- En 1991 el MCCA se fortalece con un nuevo entramado institucional sumamente complejo (que incluía: la Reunión de Presidente, la Reunión de Vicepresidentes, el Consejo de Ministros de Relaciones Exteriores, el Parlamento Centroamericano, la Corte Centroamericana de Justicia, el Comité de Enlace, y la Secretaría General) para dar origen al Sistema de Integración Centroamericana (SICA).

- En 1991 se pone en marcha la Comunidad de Estados Independientes (CEI) con la participación de Bielorrusia, Ucrania, Rusia, Armenia, Azerbaiyán, Kazajstán, Moldavia, Tayikistán, Turkmenistán, Uzbekistán y Georgia, aunque confiriéndole a las instituciones subregionales centrales una autoridad limitada.

- En 1992, con el Tratado de Maastricht, la Comunidad Europea se transforma 
en la Unión Europea, a la cual se incorporarán más tarde (1995) Austria, Finlandia y Suecia.

- En 1992 los miembros de la ASEAN acuerdan establecer una zona de libre comercio (AFTA), al tiempo que repasan sus objetivos y se amplía paulatinamente con las incorporaciones de Vietnam (1995), Laos (1997), Myanmar (1997) y Camboya (1999).

- En 1992, con el Tratado de Asunción, se crea el Mercado Común del Sur (Mercosur) entre Argentina, Brasil, Paraguay y Uruguay, con una institucionalidad semicompleja (con los siguientes órganos: el Consejo del Mercado Común, el Grupo Mercado Común, la Comisión de Comercio del Mercosur, la Secretaría Técnica del Mercosur, el Foro de Consulta y Concertación Política, la Comisión Parlamentaria Conjunta y el Foro Consultivo Económico-Social). ${ }^{31}$

- En 1992, con la Cumbre Extraordinaria de Windhoek, la institucionalidad de la SADCC es ampliada en órganos y funciones para dar lugar a la Comunidad para el Desarrollo de Sudáfrica (SADC).

- En 1994 entra en vigor el North American Free Trade Agreement (NAFTA) entre Canadá, Estados Unidos y México, que surge como un proyecto meramente intergubernamental carente de instituciones supranacionales.

- En 1994 se conforma la gran zona del Mercado Común del Este y Sur de África (Common Market for Eastern and Southern Africa, COMESA) con la participación de Angola, Egipto, Madagascar, Sudán, Burundi, Eritrea, Malawi, Swazilandia, Comores, Etiopía, Mauricio, Uganda, República Democrática del Congo, Kenia, Ruanda, Zambia, Yibuti, Libia, Seychelles y Zimbabwe.
- En 1996, con el Protocolo de Trujillo, el Pacto Andino se perfecciona para dar lugar a la Comunidad Andina de $\mathrm{Na-}$ ciones (CAN) (que operaría a través del Sistema Andino de Integración compuesto por órganos medulares como: el Consejo Presidencial Andino, el Consejo Andino de Ministros de Relaciones Exteriores, la Comisión Andina, el Parlamento Andino, el Tribunal de Justicia, el Consejo Consultivo Laboral, el Consejo Consultivo Empresarial, el Consejo Consultivo de Autoridades Municipales, y la Secretaría General) con la participación de sus mismos miembros.

- En 1999 Angola se integra a la CEEAC; en el año 2000 el South Pacific Forum es ampliado programáticamente para dar lugar al Pacific Islands Forum (Parta).

\section{Cuarta etapa (a partir de 2001): fusión}

Desde finales de la década de los noventa e inicios del siglo XXI, los distintos sistemas de integración regionales en el mundo comenzaron a acercarse entre sí y a fortalecer sus vínculos.

Sin embargo, a partir del año 2001 se ha observado un nuevo fenómeno en los sistemas de integración regional en el mundo y es que, en buena medida, han comenzado a flexibilizar sus objetivos y plazos para dar cabida a la participación e incorporación de nuevos actores interregionales, pero también a la fusión y síntesis con otros sistemas de integración vecinos.

Bajo esta nueva tendencia, que aún no precisa si desaparecerán o si subsistirán los sistemas de integración a nivel subregional, parecen estar configurándose seis sistemas cuasi continentales: el espacio económico europeo (EEE) sería un área 
común entre la Europa de los 25 y el EFTA; el Área de Libre Comercio de las Américas (ALCA), que pretende ser hemisférico, solamente alcanzaría a diluir en un tratado económico-comercial intergubernamental a sistemas como el NAFTA, el SICA y la Caricom; la Comunidad Sudamericana de Naciones (CSN) estaría construida a partir de la absorción de la CAN por el Mercosur; la CEI se proyectaría como un área euroasiática de potencial importancia; la Comunidad Económica Africana (CEA) tendría sus pilares en la UMA, la ECOWAS, la CEEAC, la SADC y el COMESA; mientras que el Foro Regional de ASEAN-ARF (ASEAN Regional Forum) convocaría a los 10 miembros plenos de la ASEAN, a las pequeñas islas integrantes del Parta y a algunos de los socios de la SAARC.

\section{A modo de conclusión}

El nuevo orden internacional de las últimas décadas, marcado por la globalización, ha sido acompañado por la formación de varios sistemas regionales y subregionales que se han adaptado a él. Hoy en día, un camino que se observa bastante posible es la morfogénesis ${ }^{32}$ hacia un sistema multipolar que tendría su peso gravitacional en cada una de las panregiones ${ }^{33}$ del mundo. Es decir, el sistema internacional podría comenzar a ser compuesto por subsistemas regionales que acabarían alterando profundamente las relaciones internacionales, de modo que las relaciones interregionales se convertirían en los principales canales de negociación y las "tradicionales" relaciones internacionales quedarían limitadas exclusivamente a las interacciones entre Estados-nación al interior de sus propias regiones.

En este sentido el fenómeno de la regionalización, además de dar una nueva configuración a las relaciones del sistema internacional, también estaría evidenciando problemas relacionados con el actual desfase existente entre el apremiante evolucionar de la realidad y el rezago teóricoepistemológico de las ciencias sociales. Desde las relaciones internacionales y la geopolítica se puede constatar que algunos de los elementos teóricos han sido dejados, por lo que es preciso avanzar hacia otras estrategias para conceptualizar las emergentes formas de organización espacial.

Si bien desde la Paz de Westfalia los Estados-nación habían sido definidos como los principales actores de los órdenes geopolíticos mundiales en curso, al considerar la noción de región como el nivel espacial — que se sitúa entre lo nacional y lo global- correspondiente a la superficie de dos o más Estados-nación, se adelantaría en una orientación cognitiva que, sin romper con el principio territorial, perfeccionaría el conocimiento de la actual transición mundial.

En este siglo XXI la humanidad entera ha llegado a un punto crítico donde se presenta la oportunidad de forjar, a partir de las regiones, un mundo más justo y más equitativo para todos, pueblos e individuos, que supere las lógicas prevalecientes en el declinante sistema-mundo moderno. El reto para las relaciones internacionales y las ciencias sociales en general, en adelante será ampliar sus horizontes de descripción e incorporar el tema de la integración regional en la construcción de una nueva teoría general de la sociedad. my

\section{Notas}

1. Rocha Valencia, Alberto (2003) Configuración política de un nuevo mundo: dimensiones politicas de lo global, lo suprarregional, lo posnacional y lo local. Guadalajara: Universidad de Guadalajara. 
2. Giddens, Anthony (1993) Consecuencias de la modernidad. Madrid: Alianza Editorial.

3. Augé, Marc (2006) Sobremodernidad. Del mundo de hoy al mundo de mañana, documento en línea consultado a través del Archivo para estudiantes de artes y humanidades de la Universidad Autónoma de Baja California. http://tijuana-artes.blogspot.com/2006/01/ sobremodernidad-del-mundo-de-hoy-al.html. Última consulta: diciembre de 2006.

4. Beck, Ulrich, Anthony Giddens, y S. Lash (1997) Modernización reflexiva. Política, tradición y estética en el orden social moderno. Madrid: Alianza Editorial.

5. Beck, Ulrich (1998) ¿Qué es la globalización? Falacias del globalismo, respuestas a la globalización. Barcelona: Paidós.

6. Bauman, Zygmunt (1999) La globalización. Consecuencias humanas. México: FCE.

7. Drucker, Peter F. (1994) La sociedad poscapitalista. Bogotá: Grupo Editorial Norma.

8. Castells, Manuel (2005a) La era de la información: economía, sociedad y cultura. La sociedad red, vol. I. México: Siglo XXI Editores, pp.: 5592.

9. Ianni, Octavio (1999) La era del globalismo. México: Siglo XXI Editores.

10. Rocha Valencia, Alberto (2001a) "El sistema político mundial del siglo XXI, un enfoque macrometapolítico", Espiral. Estudios sobre Estado y Sociedad, vol. VII, núm. 20, enero-abril. Guadalajara: Universidad de Guadalajara-CUCSH, pp. 135-159.

11. Augé, 2006.

12. Santos, Milton (2004) Por otra globalización. Del pensamiento único a la conciencia universal. Bogotá: Convenio Andrés Bello/FCE.

13. Berger, Peter L., y Thomas Luckmann (2005) La construcción social de la realidad. Madrid: Amorrortu Editores.

14. Castells, Manuel (2005b) La era de la información: economía, sociedad y cultura. El poder de la identidad, vol. II. México: Siglo XXI Editores, pp. 91-134.

15. Según el Diccionario de la Real Academia Española, por clásico(a) se entiende no sólo el "periodo de mayor amplitud de una cultura", sino también "el momento histórico de una ciencia, en el que se establecen teorías y modelos que son la base de su desarrollo posterior". Para efectos del presente trabajo, se denomina "clásico" a este momento en el sistema internacional, no por encontrarse en la mitad de la curva de campana (bell-shaped curve), sino porque en esta etapa histórica fueron establecidas las bases mínimas para el desarrollo posterior de las relaciones internacionales.

16. Merle, Marcel (1996) Un système international sans territoire?, documento en línea consultado a través del sitio Web Cultures \& Conflits, núm. 21-22: http://www.conflits.org/document267. html (última consulta junio de 2007).

17. Huntington, Samuel (2004) El choque de civilizaciones y la reconfiguración del orden mundial. Barcelona: Paidós, pp.: 45-63.

18. "Aun cuando los primeros Estados surgidos en Europa no reconocieron ninguna autoridad que estuviera por encima de los gobierno estatales, sí lograron promover un derecho internacional orientado a la creación de un marco legal mínimo que les permitiera resolver, al menos, aquellas disputas transfronterizas que no tocaran temas relacionados con la supervivencia del Estado. Es decir, paralelamente a la acepción interestatal de soberanía territorial/gubernamental se fue desarrollando un conjunto de "reglas de juego" que ordenó las relaciones entre los Estados, avaló los derechos de jurisdicción sobre sus respectivos territorios y estableció el derecho de autogobierno" (Held, David, 1997, La democracia y el orden global. Del Estado moderno al gobierno cosmopolita. Barcelona: Paidós, pp. 100-104).

Desde esta perspectiva, el territorio o exclusividad territorial del Estado no es solamente un concepto jurídico o político sino que el territorio es, ante todo, una porción determinada de espacio objeto de apropiación de un grupo político. La construcción de la historia y el devenir común de una sociedad sólo es posible mediante el emplazamiento de fronteras en espacios geográficos determinados que al interior permitan el entretejimiento de subjetividades, de identidades, de poblaciones socialmente integradas y del desarrollo económico, social y cultural de una nación.

19. Bobbio, Norberto (1997) El tercero ausente. Madrid: Cátedra.

20. Santa Cruz, Arturo (2000) Un debate teórico empíricamente ilustrado: la construcción de la soberanía japonesa, 1853-1902. Guadalajara: Universidad de Guadalajara.

21. Esta doctrina se refiere al reconocimiento de los gobiernos siempre que éstos cumplan con un control de facto y con las capacidades para cumplir obligaciones con el resto de los actores del sistema internacional. Como explica Ronning, esta doctrina fue originalmente expresada por Estados Unidos respecto al derecho de autodeterminación de la Francia revolucionaria (Ronning, C. Neale, 1965, Derecho y política en la diplomacia interamericana. México: Uteha/

MÉXICO YLACUENCADELPACÍFICO vol. 10, núm. 30 / septiembre-diciembre de 2007 
Rebasa, pp.: 8-47). Sin embargo, al convertirse Estados Unidos en potencia mundial y hegemón continental en el siglo XIX, la Doctrina Americana de Reconocimiento es convenientemente relegada por los forjadores de la política estadounidense pero recuperada y reformulada —con especificidades ideológicas y pragmáticas por diplomáticos latinoamericanos en la Doctrina Estrada (México), la Doctrina Draco (Argentina) y la Doctrina Río Branco (Brasil), por mencionar las más importantes.

22. Algunos consideran el federalismo como la primera gran corriente teórica de la integración regional, pero en mi análisis difiero de esto. El federalismo tiene sus antecedentes en las propuestas emitidas por Immanuel Kant (1724-1804), Francisco de Miranda (1750-1816), Alexander Hamilton (1757-1804), Simón Bolívar (17831830), Pierre Joseph Proudhon (1809-1865) y Justo Arosemena (1817-1896). El federalismo es ante todo una forma de gobierno, un método que en la praxis llevó a la formación de nuevos Estados-nación como Suiza, Estados Unidos o la República Federal de Alemania. En el núcleo de la teoría, la federación implica un pacto institucional y comportamental entre iguales de tal forma que la soberanía que se genera es divisible y las lealtades compartidas. Sin embargo, esta forma de gobierno que contribuyó a la creación y el robustecimiento del Estado-nación en un contexto determinado (1815-1919), difícilmente podrá en una escala espacial más amplia repetir las mismas lógicas de gobierno frente a los nuevos retos que impone la globalización. Es decir, lo que estamos presenciando a inicios del siglo XXI con los sistemas de integración regional, no es la formación de un "mega-Estado" sino el surgimiento de una nueva escala espacial regional supranacional con características únicas que, en la complejidad de las relaciones internacionales, supera por mucho las propuestas federalistas del siglo XIX.

23. Guerra Vilaboy, Sergio, y Alejo Maldonado Gallardo (2001) "Raíces histórica de la integración latinoamericana", en Carolina Crisorio, et al., Historia y perspectivas de la integración latinoamericana. Morelia: AUNA/Escuela de Historia de la Universidad Michoacana de San Nicolás de Hidalgo, pp. 50-77.

24. Morien James, Alan (1995) "La deuda de la ONU con la Sociedad de Naciones", en Modesto Seara Vázquez (comp.), Las Naciones Unidas a los cincuenta años. México: FCE, pp.: 43-60.

25. Morales Ruvalcaba, Daniel Efrén (2007) "Participación de los países latinoamericanos dentro del Foro de Cooperación Económica Asia-
Pacífico (APEC)", México y la Cuenca del Pacífico, vol. 10, núm. 28. Guadalajara: Universidad de Guadalajara, p. 100.

26. Benelux es el acrónimo formado a partir de las primeras sílabas de los nombres de tres países: Bélgica, Nederland (Países Bajos en neerlandés) y Luxemburgo. Este término ha sido usado en las relaciones internacionales para referirse a la unión aduanera denominada Unión Económica del Benelux.

27. Rossell, Mauricio, y Pedro Aguirre (1994) La Unión Europea: evolución y perspectivas. Lecciones y oportunidades para México. México: Diana, pp. 9-45.

28. Mariscal, Nicolás (2003) Teorías políticas de la integración europea. Madrid: Tecnos, pp. 89124.

29. Vacchino, Juan Mario (2001) "La Cumbre Suramericana y el desarrollo de una utopía", Revista del Sistema Económico Latinoamericano (SELA), núm. 61, Caracas, p. 38.

30. Mariscal, op. cit., p. 165.

31. Rocha Valencia, Alberto (2006) "La dimensión político-institucional creciente y dinámica del Mercosur", en Enrique Amayo Zevallos, Jaime Estay Reyno, Jaime Preciado Coronado, Alberto Rocha Valencia, y Germán Sánchez Daza (coords.), El Mercosur en la integración latinoamericana y caribeña: contextos, dimensiones y procesos. Guadalajara: Universidad de Guadalajara/Benemérita Universidad Autónoma de Puebla, pp. 165-228.

32. El sistema tiende a modificar su estado originario, en este caso, del sistema interestatal-internacional al sistema interregionalsupranacional.

33. "En 1979 Galtung proyectó un modelo que describía al mundo compuesto por 10 "superestados", puesto que aún en plena Guerra Fría bloques de Estados-nación habían dado pasos para cooperar económica o políticamente, en una tendencia que continuaría y se acrecentaría en los próximos años" (Taylor, Peter, 1994, Geografía politica. Economía mundo, Estado-nación y localidad. Madrid: Trama Editorial, pp. 93-96). Según la propuesta de Cairo, las "panregiones" no deben ser vistas exclusivamente como agrupaciones regionales de Estados, sino hay que entenderlas fundamentalmente como la lucha de un Estado o grupo de Estados por asegurarse una base más sólida para alcanzar o mantener la hegemonía mundial (Cf. Cairo Carou, Heriberto, 2003, "Panregiones: viejas y nuevas ideas geopolíticas”, en Alberto Rocha V. et al., La integración regional de América Latina en una encrucijada histórica. Guadalajara: Universidad de Guadalajara-CUCSH, p. 34. 


\section{Referencias bibliográficas}

ALADI (2007) Asociación Latinoamericana de Integración. Consulta del sitio Web oficial: http://www. aladi.org/ (última consulta julio de 2007).

Arroyo Pichardo, Graciela (2002) "Sistema mundial y subsistemas regionales ¿̇un mundo de fractales?", en Graciela Arroyo Pichardo, y Alfredo Romero Castilla (coords.), Regiones del mundo. Problemas y perspectivas: diálogos para su estudio. México: UNAM.

ASEAN (2007) Association of Southeast Asian Nations. Consulta del sitio oficial en línea: http://www.aseansec.org/ (última consulta julio de 2007).

CAN (2007) Comunidad Andina de Naciones. Consulta del sitio Web oficial auspiciado por la Secretaría General de la Comunidad Andina: http://www. comunidadandina.org/ (última consulta junio de 2007).

Caricom (2007) Caribbean Community. Consulta del sitio Web oficial auspiciado por el Caricom Secretariat: http://www.caricom.org/ (última consulta julio de 2006).

CEEAC (2007) Communauté Economique des Etats de l'Afrique Centrale. Consulta del sitio Web oficial: http://www.ceeac-eccas.org/ (última consulta julio de 2006).

Comunidad Económica del Carbón y del Acero (1951) Texto del Tratado Constitutivo de la Comunidad Europea del Carbón y del Acero, documento en línea proporcionado por El portal de la Unión Europea: http://europa.eu.int/eur-lex/lex/es/ treaties/treaties founding.htm (última consulta octubre de 2006).

Deutsch, Karl (1968) El análisis de las relaciones internacionales. Buenos Aires: Paidós.

ECOWAS (2007) Economic Community of West African Status. Consulta del sitio oficial en línea: http://www.ecowas.int/ (última consulta junio de 2007).

EFTA (2007) European Free Trade Association. Consulta del sitio oficial en línea: http://www.efta.int/ (última consulta junio de 2007).

Ferrari, Miguel Ángel (2002) El imperio estadounidense y la paz de Westfalia. Documento en línea rescatado del sitio Web La Insignia, publicado el 10 de noviembre: http://www.lainsignia.org/2002/ noviembre/int_016.htm (última consulta mayo de 2006).

Guerra-Borges, Alfredo (2002) Globalización e integración latinoamericana. México: Siglo XXI Editores/UNAM/IIE/Universidad Rafael Landívar.

Mercosur (2007) Mercado Común del Sur. Consulta del sitio Web oficial: http://www.mercosur.int/msweb/ (última consulta junio de 2007).

NAFTA (2007) North American Free Trade Agreement. Consulta del sitio Web oficial auspiciado por el NAFTA Secretariat: http://www.nafta-sec-alena.org (última consulta junio de 2007).

Parta (2007) Pacific Islands Forum. Consulta del sitio oficial en línea auspiciado por el Pacific Islands Forum Secretariat: http://www.forumsec.org.fj/ (última consulta junio de 2007).

Pearson, Frederic S., y J. Martin Rochester (2000) Relaciones internacionales: situación global en el siglo XXI. Bogotá: McGraw-Hill.

SAARC (2007) South Asian Association for Regional Cooperation. Consulta del sitio Web oficial: http:// www.saarc-sec.org/main.php (última consulta junio de 2007).

SADC (2007) Southern African Development Community. Consulta del sitio Web oficial: http://www.sadc.int (última consulta junio de 2007).

Salomón, Mónica (2001) La PESC y las teorías de la integración europea: las aportaciones de los 'nuevos intergubernamentalismos, documento en línea proporcionado por el sitio Web de la Fundación Centro de Investigación, docencia, documentación y divulgación de Relaciones Internacionales y Desarrollo, publicado en la revista CIDOB d'Afers Internacionals, núm. 56, diciembre-enero: http://www. cidob.org/castellano/publicaciones/Afers/45-46salomon.cfm (última consulta junio de 2006).

SICA (2007) Sistema de Integración Centroamericana. Consulta del sitio Web oficial auspiciado por la Secretaría General: http://www.sgsica.org/ (última consulta junio de 2007).

UE (2007) Unión Europea. Consulta del sito Web oficial: http://europa.eu/ (última consulta junio de 2007).

UMA (2007) Union du Maghreb Arabe. Consulta del sitio Web oficial auspiciado por el Secrétariat Général: http://www.maghrebarabe.org/ (última consulta junio de 2007).

Zolo, Danilo (2000) Cosmópolis: perspectivas y riesgos de un gobierno mundial. Barcelona: Paidós. 